\title{
Dialogue or Exorcism? A Rejoinder to Schempp
}

\author{
Daryl Siedentop \\ The Ohio State University
}

The editorial to the January issue of JTPE (Metzler, 1987) encouraged us to identify issues, debate, and discuss our research efforts in sport pedagogy. This echoed a plea now commonly heard at conventions and in our literaturewe need to create and sustain a dialogue about research questions, research methods and, perhaps most of all, about the assumptions that underlie our efforts. I agree. Indeed, I've made the same plea myself (Siedentop, 1983; 1986).

I was therefore pleased when I began to read the January 1987 JTPE to find that Paul Schempp proposed to "identify the limits of natural science for researching teaching physical education and to explore an alternative paradigm that may reach beyond those limits"' (p. 112). I was disappointed that what followed was an exorcism of a caricature rather than a contribution to the ongoing dialogue.

My dictionary says that an exorcism is "a verbal formula or ritual used in exorcising" and that to exorcise is "to drive a supposed evil spirit out or away by ritual charms and incantations'" (Webster's New World Dictionary, 1964, p. 511). The evil spirit in question is of course the natural science paradigm (what is referred to in other exorcisms as the quantitative paradigm-Earls, 1986). The verbal formula appears to be to construct a caricature and then to destroy it. The incantations have to do with positivism, reductionism, objectivity, observability, and the like. Out of the ashes of the exorcised spirit arises the qualitative paradigm. What follows is a partial list of Schempp's incantations, with some comments on a few issues that do warrant our serious dialogue.

Schempp started by quoting a passage about absolute, unit-based measurement, which is the tradition in the physical and biological sciences, and using it as an entry to the natural science paradigm. In fact, the quote had to do with the distinctions between radically differing measurement strategies in the behavioral sciences, namely those between the Skinnerian and the psychometric traditions. It is curious that the measurement assumptions and tactics of the Skinnerian and the ethnographic traditions have more in common than either does with the psychometric tradition. The Skinnerian behavior analyst and the ethnographer start with unembellished descriptions of what they see. In behavior analysis this

Request reprints from Daryl Siedentop, School of HPER, 309 Pomerene Hall, Columbus, $\mathrm{OH} 43210$. 
is referred to as a behavior stream and in ethnography as field notes, measurement tactics that differ markedly from the psychometric tactic of ignoring what can be seen and trying instead to measure epiphenomena-a nice little complexity that ought to warn us about trying to simplify paradigmatic differences.

Schempp's arguments relating the three supposed assumptions of a natural science paradigm (pp. 113-114) move from a researcher viewing teaching as natural phenomenon to the researcher wanting to predict and control, all for the purpose of achieving efficiency and economy in the gymnasium-and that the way the researcher does this is to ignore context and to treat students as if they were all the same, in search of the "one best method." This not only misunderstands badly what a scientific paradigm is and does, but also comes close to an ad hominem attack on quantitative researchers.

The assertion that teaching researchers assume that physical education teachers intend to teach motor skills is defended by citing the ALT-PE coding manual (p. 113). ALT-PE research has been one source of evidence that any such assumption is risky. Because one wants to study the degree to which skill development is attended to in physical education and how it is attended to says little about a researcher's views of any teacher's intentions! What it does attest to is the researcher's assumptions about the history of a field of study rather than the specific subject for any research study. How we choose what to study, starting from our various perspectives, is an issue about which some dialogue is needed.

Schempp rightly asserts that a goal of science is to "account for or control for variability in the studied environment" (p. 113), but then goes on to focus only on control. Variability is just a technical term that recognizes the fact that people behave differently-from place to place, day to day, and even moment to moment. Isn't accounting for those differences among and within a person's behavior a reasonable goal for any science, no matter what the paradigm? My sense is that both quantitative and qualitative researchers try to account for variation within and between subjects, but that how they do so differs-and that neither assumes, as Schempp asserts, that subjects, settings, or any contextual variables are "essentially the same in their natural characteristics" (p. 113).

Perhaps Schempp's most glaring misrepresentation has to do with the assertion that those in the natural sciences ignore context. As Hayes and Brownstein (1986) have recently explained, contextualism is the proper categorization for a natural science of behavior:

Behavior analysis is based on a pervasive use of a particular explanatory model: the 'act in context'. In behavior analysis any event is to be understood and even defined through a contextual analysis. The three-term contingency of radical behaviorism is a dynamic spatio-temporal contextual unit-none of the terms can be defined independently of any of the others. Radical behaviorism is so thoroughgoing in its attempts to analyze context that even the behavior of scientists as they conduct contextual analyses is to be understood through more contextual analyses (Skinner, 1945).

The explanatory model of the 'act in context' is shared by many perspectives on behavior, from certain forms of evolutionary biology to some types of cultural anthropology to Marxism. Because a basic explanatory model (or 'root metaphor') is at the core of any well-integrated and consistent world 
view, Pepper (1942) has suggested that all perspectives that rely on the 'act in context' as an explanatory model be thought of as types of the world view he calls 'contextualism'. (Hayes \& Brownstein, 1986, p. 177)

What is most interesting here is, again, the strong similarity between a radical natural science view and the qualitative view. Each is more similar, at least in this respect, than either is with, for example, current cognitive science, which is clearly a mechanistic model (using Pepper's categories). Here too the contrasting of paradigms becomes quite complex. Many natural scientists view themselves as operating within an ecological perspective-and though it was Lather (1985) who was referenced for the quote "we are both shaped and shapers of our world" (p. 8) in defense of the qualitative position, the concept referred to and even the language used to express it is consistent with the traditions and assumptions of behavioral psychology.

Schempp also is concerned about the limiting constraints of "observability" and "objectification" (p. 114), and I would be too if I held his narrow view of the issues. First, one wonders whether things like power and status, cultural and political influences are not manifested in behavior. Schempp seems to believe they are not. Second, who is arguing that one "moment" of observation is sufficient to capture anything? On the other hand, is not repeated observation of behavior in a variety of contexts and situations over a long period of time one important way to understand intentions and what he calls "biographies"? Third, he seems to consider only observation of public events as permissible in the natural sciences, but clearly there are private events that can be observed only by the person within whom they occur. Except in methodological behaviorism, which has few adherents any more, the measurement problems in a natural science of behavior are with accessibility and reliability rather than observability. The alternative measurement tactics useful for dealing with what are typically referred to as private events are reviewed well by Johnston and Pennypacker in the 1980 text, Strategies and Tactics of Human Behavioral Research.

Discussion of measurement tactics and the assumptions that underlie them is something we need to engage in. Whether quantitative or qualitative, the trustworthiness of the data is a central issue in research.

Enough is enough! All that this catalog of misconceptions serves to highlight is that there are real issues to be discussed and important similarities and differences to be explored and understood. At the AIESEP meetings in Heidelberg I raised some issues concerning the qualitative paradigm (Siedentop, 1986). I was able to do so by utilizing only the vital and healthy debates that have been going on among qualitative researchers. Similar debates abound in the so-called natural sciences, especially between cognitivists and behaviorists. These intraparadigmatic debates are very heated but often occur with some reasonable understanding of each other's positions and without the need to caricature the opposing point of view.

I see no evidence that qualitative research has been discriminated against in our journals or at our conferences. There is every reason to believe it can grow and prosper as its internal criticism mechanisms sharpen its methodologies and data reduction strategies. And, there is good reason for quantitative and qualitative researchers to engage in serious dialogue about their similarities and their 
differences. But it serves no purpose to characterize the quantitative approach as contrived, unnatural, rigid, ahistorical, and simplistic while describing the qualitative approach as natural, responsive, context relevant, flexible, and complex (Earls, 1986, p. 37). We have had enough exorcising, thank you-let's have some dialogue.

\section{References}

Earls, N. (1986). Conflicting research assumptions and complementary distinctions. Journal of Teaching in Physical Education, 6, 30-38.

Hayes, S., \& Brownstein, A. (1986). Mentalism, behavior-behavior relations and a behavior-analytic view of the purposes of science. The Behavior Analyst, 9, 175-190.

Lather, P. (1985, April). Empowering research methodologies. Paper presented at the American Educational Research Association annual meeting, Chicago.

Metzler, M. (1987). Editorial. Journal of Teaching in Physical Education, 6, 109-110.

Pepper, S.C. (1942). World hypotheses. Berkeley: University of California Press.

Schempp, P. (1987). Research on teaching in physical education: Beyond the limits of natural science. Journal of Teaching in Physical Education, 6, 111-121.

Siedentop, D. (1983). Research on teaching in physical education. In T.J. Templin \& J.K. Olson (Eds.), Teaching in physical education. Champaign, IL: Human Kinetics.

Siedentop, D. (1986, August). Sport pedagogy: Research, methods, and assumptions. Paper presented at Association Internationale d'Ecoles Superieur d'Education Physique world congress, Heidelberg, West Germany.

Skinner, B.F. (1945). The operational analysis of psychological terms. Psychological Review, 52, 270-276.

\section{Acknowledgments}

My thanks to Dr. Mary O'Sullivan for her critique of this response. 